Cahiers $d u$ MONDE RUSSE

\section{Cahiers du monde russe}

Russie - Empire russe - Union soviétique et États indépendants

48/2-3 | 2007

Les résonances de 1905

\title{
Malaise dans la culture juridique libérale en Russie après 1905
}

«Pédagogie des libertés » et éducation au droit

Michel Tissier

\section{(2) OpenEdition}

Journals

Édition électronique

URL : https://journals.openedition.org/monderusse/8995

DOI : $10.4000 /$ monderusse. 8995

ISSN : $1777-5388$

Éditeur

Éditions de l'EHESS

Édition imprimée

Date de publication : 15 avril 2007

Pagination : 185-208

ISBN : 978-2-7132-2147-7

ISSN : $1252-6576$

Référence électronique

Michel Tissier, "Malaise dans la culture juridique libérale en Russie après 1905 », Cahiers du monde russe [En ligne], 48/2-3 | 2007, mis en ligne le 01 janvier 2007, consulté le 03 septembre 2022. URL http://journals.openedition.org/monderusse/8995; DOI : https://doi.org/10.4000/monderusse.8995 
chercher : repérer : avancer

Cet article est disponible en ligne à l'adresse :

http://www.cairn.info/article.php?ID REVUE=CMR\&ID NUMPUBLIE=CMR 482\&ID ARTICLE=CMR 4820185

Malaise dans la culture juridique libérale en Russie après 1905. « Pédagogie des libertés » et éducation au droit

par MICHEL TISSIER

Editions de l'EHESS | Cahiers du monde russe

2007/2-3 - Vol 48

ISSN 1252-6576 | ISBN 9782713221477 | pages 185 à 208

Pour citer cet article :

-TISSIER M., Malaise dans la culture juridique libérale en Russie après 1905. "Pédagogie des libertés 》 et éducation au droit, Cahiers du monde russe 2007/ 2-3, Vol 48, p. 185-208.

Distribution électronique Cairn pour les Editions de l'EHESS.

(C) Editions de l'EHESS. Tous droits réservés pour tous pays.

La reproduction ou représentation de cet article, notamment par photocopie, n'est autorisée que dans les limites des conditions générales d'utilisation du site ou, le cas échéant, des conditions générales de la licence souscrite par votre établissement. Toute autre reproduction ou représentation, en tout ou partie, sous quelque forme et de quelque manière que ce soit, est interdite sauf accord préalable et écrit de l'éditeur, en dehors des cas prévus par la législation en vigueur en France. Il est précisé que son stockage dans une base de données est également interdit. 


\title{
MALAISE DANS LA CULTURE JURIDIQUE LIBÉRALE EN RUSSIE APRÈS 1905
}

\author{
« Pédagogie des libertés » et éducation au droit
}

La révolution de 1905 en Russie, répétition générale de 1917 ? Le jugement faisait florès du temps de l'Union soviétique, mais les historiens ont depuis lors fait justice de cette réputation ${ }^{1}$. Néanmoins, le motif de la répétition ne doit pas nécessairement être congédié, si l'on consent à inverser la perspective, à s'affranchir de la téléologie de la révolution, et donc aussi à considérer 1917 avant octobre. Alors, à certains égards, c'est plutôt 1917 qui répète, rejoue, recycle 1905. Un exemple de ce bégaiement après février 1917, à la lumière de l'expérience des années 19051906, peut être trouvé dans le discours sur « les libertés » et sur les réformes institutionnelles d'inspiration libérale. En comparant la place tenue par ce discours dans les deux épisodes, 1905 et 1917, on est conduit à s'interroger sur la situation de ce que nous définirons comme la « culture juridique libérale » en Russie, à chacun de ces deux moments, mais aussi dans l'intervalle.

Les années 1905-1906 furent un moment d'innovation politique remarquable en Russie, tant dans les mots d'ordre de mobilisation, que dans les méthodes de contestation adoptées. Dans le contexte de libération de la parole de ces années, bien visible à travers l'essor de la presse périodique, des tracts, des livres et des brochures, apparut pour la première fois en Russie une véritable littérature politique de masse ${ }^{2}$. Le développement de cette littérature révèle, chez la majorité des auteurs, deux objectifs complémentaires et en pratique très difficiles à dissocier. Il s'agissait, d'une part, de

1. Voir François-Xavier Coquin, 1905 : la révolution russe manquée, Bruxelles : Complexe, 1985, p. 6-7.

2. N. Rubakin, « Knižnyj priliv i knižnyj otliv » [Le flux et le reflux des livres], Sovremennyj mir, no 12, 1909, otd. II, p. 1-25, notamment p. 8 ; Jeffrey Brooks, When Russia Learned to Read: Literacy and Popular Literature, 1861-1917, Princeton : Princeton University Press, 1985 , p. 345-346. 
faire de la propagande en faveur de telle ou telle tendance politique et, d'autre part, de faire l'éducation des lecteurs visés ou de ceux à qui pouvaient être lus ces textes. Généralement, c'était « le peuple » qui était destinataire de cette littérature, même si la réalité des moyens employés par les auteurs pose le problème de leur image du peuple, et de l'adéquation de cette image avec le lectorat potentiel. L'ensemble de cette littérature constitue donc une sorte de gigantesque leçon d'éducation politique, commencée en 1905 et amplifiée durant la campagne pour les élections à la première Douma et pendant les quelques mois d'existence de cette assemblée en 1906 (les publications en 1907 sont bien moins nombreuses). Or, dans cette masse de publications, la littérature sur « les libertés » n'était pas l'apanage des partis politiques constitutionnalistes en formation à l'époque, principalement les partis constitutionneldémocrate et octobriste, ni des auteurs ou des éditeurs proches d'eux. Au contraire, le thème des libertés servit de point commun aux révolutionnaires socialistes et aux défenseurs de conceptions constitutionnalistes et libérales, dans leur opposition au régime ${ }^{3}$. Les uns et les autres faisaient face à la même difficulté. Ils devaient expliquer et faire comprendre par la population - lecteurs et électeurs potentiels - les notions de « libertés », considérées comme des concepts juridiques issus d'un savoir spécialisé et liés à des références étrangères. Le statut de ces libertés demeurait ambigu, ou controversé. On parlait de libertés « civiles », ou « individuelles », mais certains les voyaient aussi comme «politiques $»^{4}$. L'expression française classique « libertés publiques » rend assez bien compte de leur ambiguiité persistante : des libertés reconnues et garanties pour chacun, rendant à la rigueur possible la participation politique. Quoi qu'il en soit, le discours des libertés venait se superposer au vocabulaire autochtone très fortement connoté de «la liberté ». De là découlaient les nombreuses initiatives visant à vulgariser les notions juridiques sur les libertés au sein de la population russe, ce que l'on peut appeler une pédagogie des libertés. Le thème était traité de manière à peu près équivalente et avec des intentions similaires par les différents auteurs impliqués, quelles que fussent leurs préférences politiques.

En 1917, on voit réapparaître le même genre de publications. Il s'agissait parfois de la réédition de brochures sorties en 1905-1906. Il y avait aussi des brochures totalement inédites, mais leur contenu ne présentait guère d'innovations par rapport aux précédentes. Comment rendre compte de cette manière que 1917 a eu de recycler 1905 ? La réponse la plus immédiate consiste à y voir une conséquence des promesses que le régime impérial avait faites en 1905 en matière de libertés et qu'il n'avait pas tenues. Comme les Russes restaient en 1917 peu familiers des libertés, il fallait remettre l'ouvrage sur le métier. Ni la proclamation des libertés, ni même la traduction d'un tel acte déclaratif en dispositions juridiques pour garantir l'exercice de ces libertés ne rendaient inutile, du point de vue de leurs partisans, pareille œuvre pédagogique. Au contraire : c'est surtout après que le tsar eut mentionné les

3. C'est l'aspect étudié dans Linda Edmondson, «Was There a Movement for Civil Rights in Russia in 1905 ? », in Olga Crisp, Linda Edmondson, eds., Civil Rights in Imperial Russia, Oxford : Clarendon Press, 1989, p. 263-285.

4. Edmondson, « Was There a Movement... », p. 276. 
libertés dans le manifeste du 17 octobre 1905 que les brochures sur les libertés furent publiées par dizaines. En 1917, le programme et les premières déclarations du gouvernement provisoire faisaient grand cas des « libertés constitutionnelles ${ }^{5}$. Ses premières mesures incluaient la suppression des organes de la répression tsariste et diverses dispositions organisant un régime de libertés en matière de presse, d'association, de conversion religieuse, jusqu'à la convocation de l'Assemblée constituante ${ }^{6}$. C'est à partir de là (et pour cause, puisqu'il n'y avait plus de censure) que la littérature sur les libertés se mit à refleurir.

Le recensement de l'ensemble des différentes brochures publiées sur le thème des libertés en 1905-1906, d'une part, et en 1917, d'autre part, n'est pas chose aisée. C'est seulement au milieu de l'année 1907 qu'apparut la revue Knižnaja letopis' Glavnogo upravlenija po delam pečati, où était publiée, à un rythme hebdomadaire, la liste des nouvelles publications non périodiques imprimées. Cette source est utile pour recenser les brochures en 1917, mais seulement jusqu'au mois d'août, de façon assez systématique et fiable ${ }^{7}$. L'équivalent n'existe pas pour 1905-1906. Il faut donc se reporter à d'autres types de sources, mais il est difficile d'être exhaustif. Des recueils constitués à l'époque pour « recommander» aux lecteurs les brochures à lire sur tel ou tel thème, et justement sur les libertés et les questions institutionnelles en particulier, donnent des indications précieuses, mais forcément incomplètes ${ }^{8}$. Reste la recherche dans les catalogues de bibliothèques, lorsqu'elles sont dotées de fichiers thématiques adéquats, ou lorsqu'elles ont pu recueillir des collections spécialisées. C'est le cas de la Bibliothèque de documentation internationale contemporaine, à Nanterre. Elle rassemble, depuis l'entre-deux-guerres, de très nombreuses brochures de propagande publiées en 1905-1906 et en 1917, en particulier sur la question des « libertés publiques ${ }^{9}$. Encore faut-il considérer que

5. «La première déclaration du gouvernement provisoire (6 mars 1917) », citée dans Marc Ferro, La révolution de 1917, P. : Albin Michel, 1997, p. 925-927.

6. H.J. White, «Civil Rights and the Provisional Government», Crisp, Edmondson, Civil Rights..., p. 300-302.

7. Knižnaja letopis'́, no 42-44, 1917, p. 1-2.

8. Pour 1905-1906, voir par exemple Ukazatel' obščedostupnyh knig po obščestvennopolitičeskim voprosam [Index des livres pour tous publics sur les questions sociales et politiques], vyp. 1, SPb (Literaturnaja kommissija pri Vserossijskom sojuze učitelej i dejatelej po narodnomu obrazovaniju), 1906 ; Obzor literatury po izbiratel'nomu pravu [Panorama des publications sur le droit de suffrage], vyp. 1, Rostov s/ Don : Izd. A. Surat (Sklad pri knigoizdatel'stve « Donskaja Reč' » v Rostove na Donu), [1906] ; Čto čitat'? Vypusk I-yj : literatura po pravovomu voprosu [Que lire ? No 1 : littérature sur la question juridique], SPb : Izdanie Tovariščeskogo Knigoizdatel'stva, 1907. Pour 1917, voir par exemple Ukazatel' rekomenduemoj literatury po voprosam social'no-političeskim [Index de la littérature recommandée sur les questions sociales et politiques], M. : Obščestvo mladših prepodavatelej Moskovskogo Universiteta, 1917 ; et, sur les brochures de recommandations bibliographiques publiées, directement ou non, par les partis politiques en 1917, voir P.N. Bazanov, «Čto čitat' graždaninu svobodnoj Rossii...: iz istorii rekomendatel'noj bibliografii političeskih partij Rossii 1917 g. »[Que doit lire un citoyen de la Russie libre... : sur l'histoire des recommandations bibliographiques des partis politiques de Russie en 1917], Bibliografija, no 4, 1995, p. 99-106.

9. Les évolutions de «l'esprit public » figuraient parmi les objets d'étude prioritaires des anciens Musée et Bibliothèque de la guerre. Sur les brochures publiées pendant la révolution de 
des brochures au contenu juridique ou politique plus large abordaient également cette question.

La situation en 1917 semblait devoir assurer à cette littérature sur les libertés un retentissement au moins aussi grand qu'en 1905-1906. Le gouvernement provisoire était bien davantage prêt à y contribuer que n'avait pu l'être le gouvernement impérial onze ans plus tôt. Nous montrerons que, si retentissement il y eut, il fut bien plus ambigu qu'en 1905-1906. À travers le discours sur les libertés - et non sur « la liberté »-, ce n'est pas en 1917, mais en 1905-1906, que la culture juridique libérale fut promue avec le plus d'éclat dans l'histoire russe. Selon nous, ce sont les hésitations, après 1906, sur les finalités de la «culture juridique libérale » et sur les moyens de la promouvoir, qui lui ont fait perdre cet éclat. Ses partisans dans les milieux juridiques n'ont guère été capables de le lui faire retrouver. Nous le vérifierons à travers la façon dont ils concevaient l'éducation de la population russe aux libertés, auxquelles ils étaient tant attachés.

\section{La « pédagogie des libertés » : quand 1917 répète $1905 \ldots$}

En quoi consistaient précisément ces libertés ? En 1905, il y avait plusieurs expressions employées pour les désigner. Le manifeste impérial du 17 octobre chargeait le gouvernement d' " accorder à la population les fondements intangibles de la liberté civile » (graždanskaja svoboda), en précisant cette expression par l'énumération suivante : «inviolabilité de la personne, liberté de conscience, de parole, de réunion et d'association ». L'expression la plus fréquemment utilisée en 1905-1906, graždanskie prava (les droits civils), correspondait en général à cette liste, à laquelle elle ne se limitait pourtant pas. Ainsi, la liberté de la presse était aussi explicitement mentionnée par la plupart des auteurs. De même, l'inviolabilité du domicile et de la correspondance complétait l'inviolabilité de la personne. L'égalité de tous devant la loi, enfin, était généralement invoquée comme le corollaire des libertés énumérées. Autour de ce noyau, un certain nombre de variantes étaient possibles selon les auteurs : les uns insistaient sur la liberté de mouvement, les autres sur la liberté syndicale ou la liberté de faire grève. Mais toutes les libertés considérées à l'époque étaient « formelles », c'està-dire que leur garantie reposait principalement sur des procédures juridiques. Elles n'incluaient pas de droits économiques et sociaux sous la forme de «droitscréances ». Aussi, en 1905-1906, lorsqu'un auteur social-démocrate expliquait

1917 et rassemblées par la bibliothèque, voir Alexandra Dumesnil, Wilfrid Lerat, éd., Catalogue des Bibliothèque et Musée de la guerre : catalogue méthodique du fonds russe de la bibliothèque, introd. par Camille Bloch, P. : A. Costes, 1932, p. VII-VIII, 174 et suiv. La bibliothèque a aussi intégré, en 1933, un fonds de documents et d'ouvrages rassemblés par un mécène au début du siècle, le prince Bebutov. Ce prince d'origine géorgienne collectionna les traces de l'activité des milieux révolutionnaires russes de l'époque. Une très grande partie des brochures de la BDIC pour la période 1905-1906 provient de sa collection. Sur ce fonds, voir Alexandre Goriounov, Rébecca Houzel, «Fonds Bebutov (F DELTA res 811) : inventaire », Nanterre, BDIC, 2002, p. 1. 
les libertés en se réclamant de la défense des intérêts du prolétariat, il insistait sur la nécessité de garantir effectivement aux ouvriers les mêmes droits qu'aux autres classes sociales ${ }^{10}$.

Une autre expression générique était également très utilisée : prava čeloveka $i$ graždanina (les droits de l'homme et du citoyen). Toutefois son usage n'était pas systématique. Et pour les cas où elle était utilisée, il faut prendre garde à ce qu'elle recouvrait vraiment. De fait, le noyau des libertés revendiquées et promues en Russie en 1905-1906 correspond de façon seulement limitée au contenu des «droits de l'homme et du citoyen » tel qu'il fut proclamé en 1789 ou, différemment, en 1793. L'énumération très générale des «droits naturels et imprescriptibles » des déclarations françaises - liberté, propriété, sûreté et résistance à l'oppression (1789) ou égalité, liberté, sûreté et propriété (1793) — n'est reprise telle quelle ni dans les revendications des opposants au tsarisme, ni dans la pédagogie des libertés. Contrairement aux images toutes faites sur le bavardage droit-de-l'hommiste naïf de 1905, c'est moins la portée déclarative des libertés qui retenait l'attention des pédagogues des libertés, que la nécessité de les faire passer dans le droit positif, de bâtir les garanties juridiques pour cela ${ }^{11}$. De ce point de vue, les pédagogues des libertés dans la Russie de 1905 prenaient de la distance à l'égard du moment révolutionnaire français. En France, après 1789, il fallut plus d'un siècle de luttes politiques et d'élaborations juridiques, pour faire entrer dans le droit positif les libertés principales. Et cela se fit parfois même contre les principes proclamés par la révolution. L'Angleterre ou les États-Unis avaient tôt garanti l'exercice de la liberté d'association, que le régime républicain français reconnut seulement sur le tard. Par conséquent, derrière l'expression « Les droits de l'homme et du citoyen », les brochures de 1905-1906 se référaient en réalité à une histoire moins univoque et à des références plus variées que l'allusion à la révolution française ne pouvait le laisser penser.

La référence aux «droits de l'homme et du citoyen » dans certaines brochures pose encore un autre problème. À travers la mention du citoyen, l'expression d'origine française posait la question de la participation politique des individus. Or ce problème n'était pas traité par tous les auteurs sur le même plan que le thème des libertés et la question des moyens de les faire respecter. Certes, pour tous les auteurs, le fait d'expliquer les libertés avait incontestablement une dimension politique, clairement affichée, dans le refus de l'autocratie. D'ailleurs, la question des libertés était aussi fréquemment abordée dans les brochures sur les questions institutionnelles au sens large, telles que le problème de la représentation nationale, le droit de suffrage, la forme de gouvernement, la nécessité d'une constitution ou le

10. M. Balabanov, Ličnaja svoboda (Neprikosnovennost' ličnosti, žilišča, častnoj perepiski i svoboda peredviženija) [La liberté personnelle (L'inviolabilité de la personne, du domicile, de la correspondance privée et la liberté de mouvement)], 2e éd., SPb : Novyj Mir, [1906], p. 3547 (Ličnaja svoboda i proletariat : la liberté personnelle et le prolétariat).

11. Posture en adéquation avec celle de nombre de philosophes et de juristes d'Europe occidentale au XIX ${ }^{\mathrm{e}}$ siècle : voir Frédéric Worms, éd., Droits de l'homme et philosophie : une anthologie (1789-1914), P. : Presses pocket, 1993, p. 31-35. 
type de constitution à retenir ${ }^{12}$. Cependant, sur ces sujets-là, les visions présentées étaient beaucoup moins consensuelles entre les auteurs - ce qui est tout à fait conforme aux divisions entre forces politiques dans la Russie de 1905, par exemple sur la question du suffrage universel. La référence aux « droits de l'homme et du citoyen » supposait donc, chez les auteurs qui l'utilisaient, une vision plus tranchée du discours sur les institutions, où la continuité entre «droits civils » et «droits politiques » était mise en valeur. Mais à l'intérieur de ce discours, la question des libertés n'était pas traitée de manière très originale. Quel que fût le « titre » choisi, les brochures développaient en général une vision très analytique de chacune des libertés considérées, expliquant à quel problème elle devait remédier, pourquoi les Russes en avaient besoin, et comment la garantir en pratique grâce à un seul instrument légitime, celui du droit. Aussi, les références à l'histoire du droit et à la pratique juridique, à l'étranger et en Russie, constituaient bien le socle commun sur lequel s'appuyait la pédagogie des libertés. En 1905-1906, s’il n’y eut pas de mouvement organisé en faveur des libertés ${ }^{13}$, il y eut une mode, et un marché, de la «pédagogie des libertés ».

Ce constat conduit à souligner la vitalité, en 1905-1906, d'une conception libérale de la culture juridique, même si pour certains, comme les marxistes, cela correspondait à un passage obligé sur la voie du socialisme. En utilisant ici l'expression «culture juridique », on s'en tient à l'acception intellectualiste de la notion de culture, la plus classique en français, bien qu'elle ne soit pas dominante dans les usages actuels de cette notion dans les sciences sociales ${ }^{14}$. La culture juridique relève alors du domaine du savoir, et désigne l'ensemble des connaissances et des opinions (le savoir en question étant controversé et constamment reformulé) circulant, à un moment donné, sur le droit ${ }^{15}$. La culture juridique n'est pas «le droit ». Mais elle est aussi distincte des usages du droit tels qu'on peut les reconstituer, même si ceux-ci impliquent le maniement d'une certaine culture juridique, hétérogène d'un individu à l'autre ${ }^{16}$.

12. De la même manière qu'on retrouvait la question des libertés en tête de la plupart des programmes des partis politiques non traditionalistes élaborés durant cette période : voir l'anthologie constituée par A.N. Arinin, S.I. Semenov, V.V. Šelohaev, éd., Prava i svobody čeloveka $v$ programmnyh dokumentah osnovnyh političeskih partij i ob"edinenij Rossii XX vek [Les droits et les libertés de l'homme dans les documents programmatiques des principaux partis et unions politiques de Russie au XXe siècle], M. : ROSSPEN, 2002.

13. Edmondson, « Was There a Movement... », p. 281-285.

14. Voir Denys Cuche, La notion de culture dans les sciences sociales, P. : La Découverte, 2004, passim.

15. Délimiter de la sorte l'usage de la notion de culture ne signifie pas qu'on s'en tient aux « idées », par opposition aux pratiques. En analysant comment la culture juridique était constituée, étendue, diffusée, on doit aussi considérer actions et comportements individuels et collectifs. Cela est néanmoins compatible avec une définition restreinte de la culture juridique comme objet intellectuel.

16. La définition proposée ici se distingue donc de celle, plus large, retenue dans Jane Burbank, Russian Peasants Go to Court : Legal Culture in the Countryside, 1905-1917, Bloomington (Ind.) : Indiana University Press, 2004. 
Cette définition de la culture juridique n'en fait pas, cependant, un sous-ensemble de la seule culture des savants ou même des différents «professionnels du droit ». En effet toutes les connaissances et toutes les opinions doivent être prises en compte, du moment qu'elles portent sur le droit et les institutions administratives et judiciaires, et quels que soient le statut ou l'origine de ceux qui les produisent, les véhiculent ou les reçoivent. Pour la Russie du début du Xxe siècle, il faut donc entendre par « culture juridique libérale » la conception du droit qui faisait une place prépondérante aux droits de l'individu - découlant d'un principe général de liberté et reconnus comme des libertés garanties et encadrées par le droit commun -, à l'égalité de tous devant la loi - en termes de devoirs autant que de droits - et à la responsabilité juridique de ceux qui étaient chargés de faire respecter la loi. La culture juridique libérale s'opposait à la culture juridique officiellement promue dans l'Empire avant 1905 et même après. Il y eut certes des éléments de « libéralisation» de la culture juridique officielle, surtout à partir de 1905. Ces concessions n'étaient pas négligeables dans divers domaines, elles offraient par exemple des possibilités nouvelles de quitter la religion orthodoxe pour une autre confession, ou établissaient un régime nouveau pour ouvrir des associations ${ }^{17}$. Cependant, ces mesures étaient très limitées ou furent très rapidement suivies de nouvelles entraves. Plus significatifs étaient peut-être les nombreux conflits, au sein de l'administration impériale, sur la façon de faire évoluer la culture juridique officielle ${ }^{18}$ qui, toutefois, ne devint jamais une culture juridique libérale.

Qu'en est-il alors du thème des libertés et, plus généralement, de la culture juridique libérale en 1917 ? La révolution de Février ouvrit une nouvelle phase de pédagogie des libertés. Comme en 1905-1906, des dizaines de brochures sur les libertés, et plus largement sur les questions institutionnelles, furent mises en circulation à partir de ce moment ${ }^{19}$. Il serait aussi possible de voir cette pédagogie des libertés à l'œuvre dans la presse périodique ${ }^{20}$. Ici, le traitement de la question des libertés doit bien être distingué de l'usage généralisé du thème de « la liberté » en 191721. Pour les auteurs, il s'agissait bien de donner la définition de notions juridiques, d'en expliquer l'origine et la portée, et d'en justifier l'intérêt pour la Russie nouvelle dans la perspective d'une

17. Voir A.S. Tumanova, Samoderžavie i obščestvennye organizacii v Rossii (1905-1917 gody) [L'autocratie et les associations en Russie (1905-1917)], Tambov: Izd-vo TGU im. G. R. Deržavina, 2002.

18. Sur le problème de la construction d'une justice administrative, voir E.A. Pravilova, Zakonnost' i prava ličnosti : administrativnaja justicija $v$ Rossii (vtoraja polovina XIX V. oktjabr' 1917 g.) [La légalité et les droits de la personne : la justice administrative en Russie (seconde moitié du XIXe siècle - octobre 1917)], SPb : SZAGS / Obrazovanie-kul'tura, 2000.

19. Il est très difficile de déterminer leurs tirages, seules quelques estimations ponctuelles sont possibles.

20. Pour une vue d'ensemble, voir Boris I. Kolonitskii, «The Press and the Revolution », in Edward Acton, Vladimir Iu. Cherniaev, William G. Rosenberg, éd., Critical Companion to the Russian Revolution, 1914-1921, Bloomington (Ind.) : Indiana University Press, 1997, p. 381-384.

21. Ainsi, sur le «culte du combattant de la liberté », voir Orlando Figes, Boris Kolonitskii, Interpreting the Russian Revolution : the Language and Symbols of 1917, New Haven : Yale University Press, 1999, p. 74-75. 
rénovation du droit, d'une part, et d'une transformation des institutions politiques, d'autre part. La continuité entre cette pédagogie des libertés et celle qui s'était développée en 1905-1906 est patente. Certains auteurs actifs durant la «première révolution » reprirent du service. Des brochures écrites et publiées alors furent rééditées, éventuellement avec des changements mineurs. Ainsi Nikolaj Petrovič Družinin, un publiciste spécialiste des questions juridiques et de la vulgarisation du droit positif avant 1905, avait publié en 1906 plusieurs brochures sur les questions institutionnelles. L'une d'elles, intitulée « Les droits de l'homme et du citoyen », fut réimprimée sans aucun changement en $1917^{22}$. Un autre titre du même auteur, «Les paysans-citoyens », publié une première fois en 1906, en principe à destination des paysans, ressortit en 1917 avec quelques modifications ${ }^{23}$. Pavel Grigor'evič Mižuev, autre auteur prolifique et spécialiste des questions d'enseignement et d'éducation, visait généralement un public plus instruit. Sa brochure « Les droits de l'homme et du citoyen » connut deux éditions, la première en 1906, la seconde en 191724 .

D'autre part, des auteurs déjà actifs en 1905-1906 produisirent aussi en 1917 des brochures inédites. Le 8 mai 1917, le même Mižuev signa un contrat avec le grand éditeur moscovite Sytin, en personne, pour la publication et la diffusion de treize brochures déjà prêtes, dont le contenu politique et historique était prétendument « à la portée de tous ». En 1917, Mižuev ne proposa pas à Sytin sa brochure traitant directement des libertés, rééditée ailleurs. Mais plusieurs titres portés au contrat concernaient les questions institutionnelles, à travers l'exemple de pays étrangers comme les États-Unis («La naissance de la première grande république démocratique »), la Suisse («La république démocratique confédérative en Suisse »), ou des thèmes particuliers comme le droit de vote («Principes fondamentaux du droit de vote », «Le droit de vote dans les États fédéraux d'Europe, d'Amérique et d'Australie », « Les systèmes électoraux dans les pays de suffrage universel »). Le contrat prévoyait pour chacune des brochures un premier tirage de quinze mille exemplaires, et fixait les conditions des éventuels tirages ultérieurs ${ }^{25}$. Mižuev n'était pas le seul vétéran de

22. N.P. Družinin, Prava čeloveka i graždanina (iz knigi : Izbirateli i narodnye predstaviteli) [Les droits de l'homme et du citoyen (extrait du livre : Les électeurs et les représentants du peuple)], M. : Izdanie D.I. Tihomirova, 1906, 32 p., au prix de 10 kopecks. À 25 kopecks, la deuxième édition, sous le même titre (32 p.), fut publiée en 1917 à Moscou, par E.N. Tihomirova, veuve du pédagogue et éditeur Dmitrij Ivanovič Tihomirov, à l'enseigne des revues Junaja Rossija et Pedagogičeskij listok.

23. N.P. Družinin, Krest jane-graždane : narodnoe čtenie [Les paysans-citoyens : lecture populaire], M. : Izdanie D.I. Tihomirova, 1906, 64 p. : d'une longueur inhabituelle pour le public théoriquement visé, la brochure était affichée au prix déjà élevé de 20 kopecks, mais la renommée de l'éditeur et de l'auteur dans les milieux pédagogiques pouvait leur laisser espérer des ventes auprès des bibliothèques populaires ou d'autres structures collectives. La brochure fut rééditée en 1917 à Moscou, avec un nouveau sous-titre et une introduction inédite. Le thème des libertés est traité dans la brochure p. 32-40 (1 re éd., 1906).

24.P.G. Mižuev, Prava čeloveka i graždanina [Les droits de l'homme et du citoyen], $\mathrm{SPb}$ : Vseobščaja biblioteka G.F. L'voviča, 1906, IV-115 p., 25 kopecks; idem, Prava čeloveka i graždanina, Petrograd : M.A. Jasnyj (Biblioteka « Svoboda »), 1917,63 p. (pas de prix indiqué).

25. Muzej I.D. Sytina [Musée I.D. Sytin], op. 1 (Kollekcii arhivnyh materialov vystavočnogo centra "U knigoizdatelja I.D. Sytina") [Collections des documents d'archive du centre d'exposition « Chez l'éditeur I.D. Sytin »], d. 53,1. 1. 
la pédagogie des libertés de 1905 à remettre son ouvrage sur le métier en 1917. C'était aussi le cas d'Ol'ga Akimovna Vol'kenštejn, proche des socialistes-révolutionnaires, très engagée dans la lutte pour l'émancipation des femmes. Plusieurs de ses brochures sur les libertés avaient été publiées par les éditions «Donskaja Reč” » en 1906²6. En 1917 Vol'kenštejn fut à nouveau très productive ${ }^{27}$. Hormis les auteurs déjà actifs en 1905-1906, de nombreux nouveaux auteurs s'emparèrent du même sujet.

Pour chacune des deux périodes révolutionnaires, les brochures consacrées aux libertés se comptent par dizaines. S'y ajoutent tous les titres consacrés plus généralement aux questions institutionnelles, dans lesquelles la question des libertés était souvent abordée. Cette thématique était certes, dans l'ensemble de la littérature politique, moins brûlante que la question agraire ou la question nationale : cette position secondaire même est un élément commun aux deux périodes. En 1917 comme en 1905, les auteurs avaient des profils professionnels divers et des orientations politiques variées. Mais leurs explications et leurs références restaient très homogènes. Ainsi, par exemple, la référence à l'Angleterre était un trait général, y compris dans les brochures intitulées «Les droits de l'homme et du citoyen ». En matière de respect des libertés, c'était non seulement l'histoire anglaise, mais aussi la pratique contemporaine dans ce pays qui étaient données en modèle. Ce constat est valable pour tous les auteurs, que leur préférence politique allât en direction des cadets, des socialistes-révolutionnaires, ou des sociaux-démocrates mencheviks ${ }^{28}$. Au total, il n'y a que des différences marginales de contenu entre les brochures publiées en 1905-1906 et celles de 1917.

Mais si 1917 répète 1905, si des éléments fondamentaux de la culture juridique libérale font toujours l'objet d'un assez large consensus chez les auteurs, la pédagogie des libertés en 1917 n'a certainement pas la portée qu'elle eut en 1905-1906. La « réception » de cette pédagogie constitue un problème délicat qu'il n'est pas possible d'étudier ici. Les brochures sont la trace la plus tangible de cette pédagogie. Il est difficile de savoir dans quelle mesure et comment elles étaient lues, elles témoignent

26. O.A. Vol’kenštejn, Dlja čego nužna svoboda slova i sobranij-shodok [À quoi servent la liberté de parole et la liberté de réunion ou d'assemblée], Rostov s/ Don : Donskaja Reč', 1906, 8 p. ; eadem, Počemu u nas trebujut neprikosnovennosti ličnosti i žilišča [Pourquoi les Russes exigent l'inviolabilité de la personne et du domicile], Rostov s/ Don : Donskaja Reč', [1906], 8 p. ; et encore d'autres titres sur l'histoire des conquêtes libérales et démocratiques en Angleterre et aux États-Unis, et sur la Révolution française. Sur l'éditeur, voir N.S. Travuškin, «Izdatel'stvo "Donskaja reč”" » [Les éditions «La parole du Don »], Kniga, issledovanija i materialy : sbornik, vyp. 21, M. : Kniga, 1970, p. 106-123.

27. Là encore, de nombreux titres, sous son nom ou sous le pseudonyme d'Ol'govič, sur la Suisse, les élections en Angleterre, le suffrage universel, etc. Sur les libertés mêmes, elle publie au moins deux éditions d'une nouvelle brochure: Neprikosnovennost' ličnosti $i$ žilišča [L'inviolabilité de la personne et du domicile], Petrograd: Osvoboždennaja Rossija (Vremennyj komitet Gosudarstvennoj Dumy), [1917], 15 p., et la brochure Prava čeloveka $i$ graždanina [Les droits de l'homme et du citoyen], Petrograd-M. : Kniga, [1917], 16 p.

28. Du côté des mencheviks en 1917, voir un exemple d'utilisation systématique du modèle anglais : Iv. Alekseev, Kakie svobody nužny graždanam [De quelles libertés ont besoin les citoyens], [M.] : Social-demokratičeskoe izdatel'stvo « Delo », 1917 (Biblioteka social-demokrata), 16 p., 12 kopecks. Les bolcheviks ne se préoccupaient guère du sujet, sauf sous des aspects plus restreints comme la question de la liberté de conscience. 
néanmoins d'un discours général, visible aussi dans la presse. Cela ne signifie pourtant pas que cette forme de pédagogie suffisait à créer l'intérêt pour le sujet traité : celui-ci pouvait lui préexister et s'étendre par des canaux différents. Elle contribuait sans doute à entretenir cet intérêt, peut-être au risque de le banaliser. Cependant, une constatation simple peut être faite ici, sans aborder la question des conditions et des effets exacts de la diffusion de cette pédagogie. Dans les nombreuses motions ou pétitions rédigées par des communautés paysannes ou par des collectifs ouvriers, la place accordée au thème des libertés d'une révolution à l'autre n'est pas la même ${ }^{29}$. En 1905-1906, le thème était très largement présent. En 1917 il l'est beaucoup moins, alors même que les questions institutionnelles demeurent bien représentées dans les revendications de la population en 1917, à travers la demande du suffrage universel, l'exigence d'une décentralisation ou celle de l'institution d'une «république démocratique », et avec la perspective de la convocation de l'Assemblée constituante. Mais en 1917 ces différents thèmes - même la définition du suffrage « universel » - font l'objet de divergences d'interprétation infiniment plus grandes que ce n'est le cas pour « les libertés », dont la définition et le champ d'application, paraissent plus stables, mieux fondées sur l'expérience juridique de pays comme la Grande-Bretagne, les États-Unis ou la France ${ }^{30}$.

Ce qui pose donc problème, c'est la relation entre la pédagogie des libertés, comme élément de promotion de la culture juridique libérale, et le « langage de la révolution » en général, pour reprendre l'expression des historiens Orlando Figes et Boris Ivanovič Kolonickij ${ }^{31}$. Or ce langage était très ambigu. Le caractère polysémique du mot «démocratie» en fournit l'illustration la mieux documentée. B. Kolonickij a montré les contextes très différents dans lesquels il était employé dans la Russie révolutionnaire de 1917. Bien loin de désigner seulement un type de régime politique - et même dans ce cas, l'ambiguiité demeurait - , le mot « démocratie » s'appliquait très souvent à une couche de la population en particulier, les classes populaires, ou à un camp politique ${ }^{32}$. Ces connotations du mot

29. Pour comparaison, voir d'une part les documents rassemblés dans L.T. Senčakova, éd., Prigovory i nakazy krest'jan Central'noj Rossii, 1905-1907gg.: sbornik dokumentov [Motions et pétitions des paysans de Russie centrale, 1905-1907 : recueil de documents], M. : Éditorial URSS, 2000, ainsi que l'étude du même auteur : eadem, Prigovory i nakazy Rossijskogo krest'janstva 1905-1907 gg. : po materialam central'nyh gubernij [Motions et pétitions de la paysannerie russe en 1905-1907 : à partir de documents des provinces centrales], M. : IRI RAN, 1994, t. 2, p. 287-298 ; et, d'autre part, le chapitre consacré aux « cahiers de la révolution russe : ouvriers, paysans, soldats » dans Ferro, Révolution, p. 170-203.

30. Mais si la déclaration des droits de l'homme et du citoyen est souvent citée, la situation juridique de la France républicaine dans le domaine des libertés est rarement prise en exemple. Même en tant que « république », la France est souvent concurrencée par d'autres modèles jugés très attractifs, par leur caractère fédéral ou confédéral : les États-Unis, la Suisse.

31. Figes, Kolonitskii, Interpreting... ; voir aussi Mark D. Steinberg, Voices of Revolution, 1917, New Haven : Yale University Press, p. 1-35.

32. Voir Boris Ivanovich Kolonitskii, "Democracy" in the Political Consciousness of the February Revolution » [1 11e éd. : 1998], Rex A. Wade, éd., Revolutionary Russia : New Approaches, NY : Routledge, 2004, p. 75-89; idem, « Jazyk demokratii : problemy "perevoda" tekstov epohi revoljucii 1917 goda » [La langue de la démocratie : problèmes de "traduction" des textes de l'époque de la révolution de 1917], inédit (je remercie l'auteur de m'avoir communiqué ce texte). 
« démocratie », surtout dans le vocabulaire des socialistes-révolutionnaires et des sociaux-démocrates, entraient en contradiction avec les interprétations conformes à la culture juridique libérale que le mot véhiculait par ailleurs, supposant l'affirmation de droits universels. Selon Mark D. Steinberg, l'interprétation des usages du mot « liberté », au singulier, en 1917, peut suivre globalement le même schéma ${ }^{33}$. Parallèlement à la pédagogie des libertés menée dans la Russie de 1917 dans une perspective universaliste, le « langage de la révolution » comprenait donc une forte composante particulariste, insistant sur les frontières et les antagonismes entre les classes sociales. Il y avait ainsi une concurrence, implicite le plus souvent, entre deux langages des droits et des libertés. La situation de la culture juridique libérale en 1917 apparaît donc paradoxale. Les références fondamentales de cette culture qu'étaient les libertés individuelles, droit de propriété excepté ${ }^{34}$, étaient promues à travers la pédagogie des libertés de manière relativement homogène. Mais, sur tous les autres sujets institutionnels, les positions divergeaient à tel point que les conceptions des libertés en étaient forcément affectées. Ce qui « relativisait » l'universalisme présumé des libertés, au point de le nier. C'est en ce sens que, comparée à ce qu'elle avait été en 1905-1906, la pédagogie des libertés en 1917 était dépassée.

D’un côté, la répétition de la pédagogie des libertés en 1917 montre que la culture juridique libérale était plus répandue chez les Russes éduqués inspirés par le progressisme qu'on ne le reconnaît en général. D'un autre côté, en décalage avec un particularisme de classe en plein essor, la pédagogie des libertés portait à faux. En 1905-1906, cette pédagogie avait contribué à faire largement circuler les notions de libertés individuelles. Il est difficile de dire quelle portée exacte le discours des pédagogues avait eue. Mais il avait alors été partiellement en phase avec les revendications exprimées par des communautés paysannes ou des collectifs d'ouvriers. En 1917, au contraire, la pédagogie des libertés manquait désormais singulièrement de points d'appui. Comment comprendre cet écart, et l'évolution entre les deux moments révolutionnaires? Bien entendu, de multiples facteurs externes à la culture juridique libérale entrent en ligne de compte, à commencer par tout ce qui venait renforcer le langage de classe : l'évolution du mouvement ouvrier, divisé mais radicalisé pendant la guerre, ou encore les affrontements sur la question agraire. La stratégie des partis politiques se réclamant de la tradition libérale, et leurs choix tactiques, sont sans doute un autre facteur à considérer ${ }^{35}$. Mais nous nous concentrerons ici sur les facteurs internes à la culture juridique libérale.

33. Steinberg, Voices..., p. 8-14. Voir aussi White, « Civil Rights... », p. 288-294.

34. Cependant ce n'est pas le droit de propriété qui définit spécifiquement la culture juridique libérale, contrairement à la vision qu'en présente Richard Pipes, Property and Freedom, Londres: Harvill Press, 1999. Sur la divergence entre libéralisme politique et libéralisme économique, voir Lucien Jaume, La liberté et la loi : les origines philosophiques du libéralisme, P. : Fayard, 2000. Pour un exemple, dans l'histoire russe, de défense du droit de propriété sans lien avec la culture juridique libérale, voir Don C. Rawson, Russian Rightists and the Revolution of 1905, Cambridge : Cambridge University Press, 1995, p. 29, 41-45, 230.

35. Voir F.A. Gajda, Liberal'naja oppozicija na putjah $k$ vlasti (1914-vesna 1917 g.) [L'opposition libérale en route vers le pouvoir (1914-printemps 1917)], M. : ROSSPEN, 2003. 
Comment a-t-elle évolué après la première expérience de pédagogie des libertés en 1905-1906?

\section{Les libertés et le droit : le problème de l'éducation}

La source la mieux connue sur la situation de la culture juridique libérale en Russie après 1905 est la contribution du juriste Bodgan Aleksandrovič Kistjakovskij au célèbre recueil Vehi en 1909, sous le titre : « Pour la défense du droit (l'intelligentsia et la conscience du droit) $»^{36}$. Les commentateurs ont souvent vu dans ce texte le témoignage décisif sur la faiblesse de la culture juridique libérale en Russie, bien que Kistjakovskij ait omis d'y défendre le droit de propriété, comme l'a noté Richard Wortman ${ }^{37}$. La contribution de Kistjakovskij est une charge contre l'intelligentsia, accusée d'ignorance et de mépris pour le droit aussi bien comme valeur que comme ensemble de règles opposables à tous les individus en société. Kistjakovskij y défendait les libertés individuelles, pour lesquelles il luttait aussi politiquement, mais il plaidait, en même temps, pour le respect du droit en vigueur dans l'empire. Il le faisait avec d'autant plus de force que, selon lui, le manifeste du 17 octobre 1905 avait reconnu la valeur de « la liberté civile » et que les lois fondamentales de 1906 avaient installé les bases d'un régime constitutionnel. Pour lui, c'était légalement, dans le respect du droit positif, avec toutes ses insuffisances, qu'il fallait œuvrer de manière à faire reconnaître progressivement les droits subjectifs auxquels il croyait. Kistjakovskij considérait que, de son côté, l'intelligentsia n'était familière ni avec le droit impérial, qu'elle s'honorait de haïr par anti-despotisme, ni avec l'idée des libertés formelles, qu'elle méprisait au nom du réalisme.

Les mises en cause de Kistjakovskij reposent sur des catégories controversées, non seulement dans l'historiographie, mais déjà à l'époque ${ }^{38}$. Qu'est-ce que cette « intelligentsia » qu'il pointait du doigt à l'instar des autres auteurs de Vehi, dont il se distinguait pourtant à maints égards, notamment parce qu'il continuait à considérer le socialisme comme un objectif à atteindre ${ }^{39}$ ? Dans son article, l'intelligentsia était caractérisée principalement par son engagement politique contre le

36. B. Kistjakovskij, «V zaščitu prava (intelligencija i pravosoznanie) » [Pour la défense du droit (l'intelligentsia et la conscience du droit)], Vehi : sbornik statej o russkoj intelligencii,

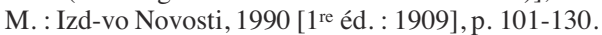

37. Richard Wortman, «Property Rights, Populism, and Russian Political Culture », dans Crisp, Edmondson, Civil Rights..., p. 13.

38. Sur le concept d'intelligentsia dans ses usages de l'époque, voir Boris I. Kolonickij, «Les identités de l'intelligentsia russe et l'anti-intellectualisme, fin du XIX ${ }^{\mathrm{e}}$-début du XX $\mathrm{XX}^{\mathrm{e}}$ siècle », Cahiers du Monde russe, 43(4), 2002, p. 601-616.

39. Et, s'il appelait l'intelligentsia à se concentrer sur «son monde intérieur », «afin de le rafraîchir et de l'assainir » (Kistjakovskij, «V zaščitu... »,p. 130), il ne partageait pas la vision religieuse de plusieurs de ses coauteurs. Voir Susan Heuman, Kistiakovsky : the Struggle for National and Constitutional Rights in the Last Years of Tsarism, Cambridge : Harvard University Press, 1998, p. 96-99 ; et Andrzej Walicki, Legal Philosophies of Russian Liberalism, Notre Dame (Ind.) : University of Notre Dame Press, 1992 [1 1réd. : 1987], p. 374-376, 388, 394. 
régime, que cet engagement fût révolutionnaire, avec l'exemple des populistes ou des sociaux-démocrates, ou plus modéré, avec le cas des cadets également critiqués. Mais l'intelligentsia avait une autre caractéristique majeure, que l'auteur n'explicitait pas : la position unique qu'elle était censée occuper dans la société russe. C'était une position charnière, celle d'un groupe social défini par son niveau d'éducation et par son rapport au savoir, conçu comme l'instrument éminent de l'émancipation individuelle et collective du peuple russe - et des autres peuples de l'empire, d'ailleurs ${ }^{40}$. Pour cette raison précisément, l'intelligentsia était capable d'exercer une influence déterminante sur le reste de la population, elle devait servir d'exemple, ou de force d'entraînement. Ce rôle éducateur de l'intelligentsia était un lieu commun, même s'il était contesté dans certains milieux ${ }^{41}$. En recommandant à l'intelligentsia de se familiariser avec le droit et de se constituer une culture juridique, Kistjakovskij avait en vue l'extension au domaine du droit du rôle éducateur de l'intelligentsia dans la société russe.

Pour en mesurer les conséquences, il faut comprendre ce que Kistjakovskij entendait par « conscience du droit» (ou « conscience juridique »). Là encore, il s'agit d'une catégorie moins évidente qu'il n'y paraît. Les difficultés qu'elle pose sont rarement perçues par les historiens ${ }^{42}$. À l'origine, cette notion fut probablement introduite en Russie au milieu du XIX ${ }^{e}$ siècle sous l'influence allemande de l'«école historique du droit ». Selon les fondateurs de cette école, Friedrich Karl von Savigny et Georg Friedrich Puchta, la « conscience du droit » est l'un des traits qui intègrent « les membres d'un peuple» «en une association qui repose sur une affinité physique et spirituelle», comme la langue ou la religion ${ }^{43}$. La « conscience juridique » dépend donc du « caractère national » qui détermine les formes prises par le droit, et en premier lieu les coutumes. Elle se développe sans relation avec une quelconque action positive visant à éduquer le peuple considéré. Cependant, les spécialistes russes du droit qui ont appliqué cette notion à la réalité locale se sont écartés de cette acception originelle, même s'ils en ont gardé un grand intérêt pour le problème du droit coutumier. Les réformes judiciaires des années 1860 ont été déterminantes, parce qu'elles ont orienté le débat sur la question de savoir quel était le degré de conscience juridique de la population, avant tout des paysans. Les juristes russes se divisaient sur le niveau d'élaboration et la valeur du droit coutumier, susceptibles de révéler ce degré de conscience juridique ${ }^{44}$. Cependant ces

40. Sur l'engagement de Kistjakovskij en faveur des droits nationaux du peuple ukrainien, voir Heuman, Kistiakovsky..., p. 113-146.

41. Kolonickij, «Les identités... », p. 609-611.

42. D'autant que s'ajoute un autre problème, lié à la réactivation de la notion par la sociologie du droit contemporaine. Ces usages sociologiques sont eux-mêmes abondamment discutés : voir Jérôme Pélisse, « A-t-on conscience du droit ? Autour des Legal Consciousness Studies », Genèses, no 59, 2005, p. 114-130.

43. Georg Friedrich Puchta, «Encyclopédie », traduit par Olivier Jouanjan, dans « L'esprit de l'École historique du droit », Annales de la Faculté de droit de Strasbourg, no 7, 2004, p. 47.

44. Voir C.A. Frierson, Peasant Icons : Representations of Rural People in Late NineteenthCentury Russia, Oxford : Oxford University Press, 1993, p. 64-69. 
spécialistes étaient implicitement d'accord pour considérer que la conscience du droit pouvait se développer, être éduquée. Ils attribuaient généralement un rôle essentiel aux tribunaux dans ce but, même s'ils s'opposaient sur les modalités pratiques de cette «éducation » à travers les institutions judiciaires, et surtout sur la capacité des tribunaux paysans à remplir ce rôle ${ }^{45}$. À partir de cette même conception générale de la conscience juridique, une nouvelle démarche pour la développer connut un certain engouement à la fin du XIX ${ }^{\mathrm{e}}$ siècle : diffuser une « littérature juridique pour le peuple », en s'appuyant sur les progrès de l'alphabétisation dans la population.

C'est donc selon cette vision éducative de la conscience juridique que raisonnait Kistjakovskij au début du XX siècle. Cependant, à la faveur du renouvellement des positions théoriques sur le droit, le juridique dans la conscience juridique fut aussi redéfini. L'importance du néo-kantisme et les appels au renouveau des théories du droit naturel contribuèrent à y introduire une autre dimension que la mesure du degré de respect et de connaissance du droit. Il s'agissait de la conscience que l'individu doit avoir de l'existence de droits irréductibles, pour lui et pour les autres. Les libertés devaient traduire cette conscience dans le droit positif. Kistjakovskij faisait partie des promoteurs de cette conception de la conscience juridique, aux côtés d'autres grands juristes, même si leurs bases théoriques divergeaient parfois ${ }^{46}$.

De ces conceptions générales, et de la structure de l'article de Kistjakovskij, découlent plusieurs questions centrales pour comprendre la situation de la culture juridique libérale après 1905. D’abord, qui faut-il éduquer? Sur quoi doit porter une éducation à même de développer la conscience juridique ? En fonction de cela, qui est le mieux placé pour mener cette éducation et quelles formes doit-elle prendre ? Nous examinerons d'abord les réponses que Kistjakovskij donnait en 1909 aux deux premières questions, en les confrontant à l'expérience des années 1905-1906. Cette confrontation permettra de saisir comment se noue le malaise dans la culture juridique libérale. On essaiera ensuite de montrer que la réponse proposée par Kistjakovskij à la troisième et dernière question n'a pas permis de résorber ce malaise entre 1905 et 1917.

On l'a vu, pour Kistjakovskij, la conscience juridique de l'intelligentsia était insuffisamment développée, et il fallait agir là-dessus. C'est l'intelligentsia qui devait être éduquée en priorité : donc pas le peuple, ce qui était nouveau. Pour remédier à ce déficit de conscience juridique - c'est la réponse à la deuxième question - l'action éducative devait porter à la fois sur l'importance des libertés individuelles, et sur le respect pour le droit en vigueur, les formes et les procédures juridiques. Les historiens

45. Sur ces oppositions, voir C.A. Frierson, «Rural Justice in Public Opinion : the Volost' Court Debate, 1861-1912», Slavonic and East European review, 64 (4), 1986, p. 526-545 ; C. Gaudin, « Tribunaux paysans en Russie, 1889-1914 », Histoire sociale / Social History, 30 (59), 1997, p. 109-126.

46. Pour une approche différente, voir P.I. Novgorodcev, Vvedenie v filosofiju prava : krizis sovremennogo pravosoznanija [Introduction à la philosophie du droit : la crise de la conscience juridique contemporaine], SPb : Lan’, 2000 [1 re éd. : 1909], notamment p. 11-13. Walicki, Legal Philosophies, p. 291-341, présente en détail la pensée de Novgorodcev, à côté de celle de Kistjakovskij. 
sont divisés sur la justesse de l'accusation portée par Kistjakovskij contre l'intelligentsia. Tout un courant historiographique a justifié son point de vue, en stigmatisant le «faux » libéralisme de la plupart des cadets, vrais radicaux ${ }^{47}$. Plus récemment, d'autres historiens ont cherché à évaluer la pertinence du jugement de Kistjakovskij en s'intéressant à la place accordée au droit dans le débat public en Russie au début du $\mathrm{XX}^{\mathrm{e}}$ siècle ${ }^{48}$. Il en ressort un tableau de la situation de la culture juridique assez différent de la vision négative qu'en proposait Kistjakovskij. Le cas des débats sur la législation sur le mariage et le droit de la famille, étudié par William Wagner, montre qu'il existait un espace de discussion des problèmes juridiques, et que la culture juridique officielle et la culture juridique libérale convergeaient partiellement pour faire évoluer le droit en tenant compte des changements sociaux.

Or un biais d'un autre type se fait jour également dans l'article de Kistjakovskij, à l'examen du problème de l'éducation aux libertés. Il faut, bien entendu, faire la part des intentions polémiques du recueil Vehi. Kistjakovskij reprochait aux partis politiques créés autour de 1905 de n'avoir pas su promouvoir les libertés, et de n'avoir pas tiré les conséquences des principes de liberté dans leur propre pratique organisationnelle. Mais l'action menée sous la forme de la pédagogie des libertés durant ces années ne retenait absolument pas son attention. Cette pédagogie n'avait certes pas été un mouvement organisé, son audience était restée limitée, elle avait été diluée dans la masse de la littérature politique. Du moins aurait-elle pu avoir, à ses yeux, le mérite d'exister, puisqu'elle correspondait à certaines de ses attentes. De plus Kistjakovskij y avait lui-même contribué en écrivant pour des périodiques, entre janvier 1905 et juin 1907, divers articles sur les droits individuels, sur la représentation nationale, et sur d'autres questions de droit public ${ }^{49}$. Il ne fut pas le seul juriste d'envergure, ni le seul savant à se consacrer à cette tâche d'éducation de la population russe, en rédigeant des articles ou des brochures. Maksim Maksimovič Kovalevskij, à la fois juriste, sociologue et historien éminent, publia à son retour en Russie en 1905 plusieurs brochures consacrées spécifiquement aux libertés et aux questions institutionnelles ${ }^{50}$. Le statisticien Evgenij Nikitič

47. Par exemple Leonard Schapiro, «The Vekhi Group and the Mystique of Revolution » [1955], dans Leonard Schapiro, Russian Studies, NY : Viking, 1987, p. 68-92.

48. Voir William Wagner, « Civil Law, Individual Rights, and Judicial Activism in Late Imperial Russia », in Peter H.Jr. Solomon, éd., Reforming Justice in Russia, 1864-1996 : Power, Culture, and the Limits of Legal Order, Armonk (NY) : M.E. Sharpe, 1997, p. 21-26, 35.

49. Voir Heuman, Kistiakovsky..., p. 29-31, et 193-194 pour la bibliographie des travaux de Kistjakovskij. Il écrivit notamment dès janvier 1905 un article dans Voprosy žizni sur «les droits de l'homme et du citoyen », donc très tôt par rapport au moment le plus intense de la pédagogie des libertés, après le manifeste d'octobre (voir des extraits en français dans Worms, Droits, p. 444-450).

50. M.M. Kovalevskij, Russkaja konstitucija. I. Svobody: očerk [La constitution russe. $1^{\text {re }}$ partie : aperçu sur les libertés], 2e éd., SPb, 1906 (Političeskaja Biblioteka «Birževyh Vedomostej »), 48 p. ; idem, Učenie o ličnyh pravah [Leçon sur les droits de la personne], M. Izdanie V.M. Sablina, 1906 (Političeskaja Biblioteka), 42 p. (reprise d'un article dans Russkaja mysl' en 1905). Voir D. Čil'jani, «Pozitivistkaja učenost', pedagogičeskie ustremlenija i liberal'naja politika v rabotah M.M. Kovalevskogo » [Savoir positiviste, visées pédagogiques et politique libérale dans les travaux de M.M. Kovalevskij], dans Vlast' $i$ nauka, učenye $i$ vlast' : 1880-e-načalo 1920-h godov, SPb : Izd-vo Dmitrij Bulanin, 2003, p. 379-401. 
Tarnovskij, qui avait des fonctions officielles puisqu'il dirigeait la section statistique du ministère de la Justice, fit paraître lui aussi une brochure intitulée «Quatre libertés », en 190651. Les contributions de ces savants politiquement modérés étaient d'un accès difficile. Mais elles venaient s'ajouter aux efforts des autres auteurs de brochures sur les libertés, orientés dans la même direction en dépit de leurs divergences politiques et stylistiques.

En passant sous silence toutes ces initiatives dans son article pour Vehi et en attaquant l'intelligentsia, Kistjakovskij évitait d'identifier le dilemme de la culture juridique libérale. En effet, la conception libérale de la conscience du droit, comme échelle mesurant à la fois la valeur attribuée aux libertés et le respect pour le droit positif, recelait une tension que la séquence formée par la période d'avant 1905 et par la révolution avait clairement manifestée. Kistjakovskij dénonçait les appels répétés de l'intelligentsia en faveur d'un droit nouveau. Il est vrai que, en 19051906, la pédagogie des libertés avait justement insisté sur la nécessité de réformer le droit russe pour y introduire les droits individuels, et en même temps pour former la conscience juridique du peuple russe. Dans ces circonstances, cela ne pouvait se faire sans critiquer la culture juridique officielle, restée jusque là sourde à l'exigence des libertés.

C'est même de cette façon que la culture juridique libérale s'était affirmée dans l'empire avant 1905. Des auteurs libéraux critiquaient la littérature de vulgarisation du droit de l'empire qui, depuis la fin des années 1880, avait pour but de diffuser les connaissances juridiques auprès de la population. Le juriste et publiciste Iossif Vladimirovič Gessen fit ainsi en 1901 une critique virulente de cette littérature, parce qu'elle diffusait la culture juridique officielle sans réflexion sur le droit luimême, ni sur la relation entre « le droit » en vigueur et « les droits » des individus ${ }^{52}$. À ce moment-là, Gessen appelait de ses vœux l'essor d'une autre littérature de vulgarisation juridique, qui aurait eu pour tâche de diffuser les principes de la culture juridique libérale : l'importance du droit, le respect de la légalité, la reconnaissance des libertés. Aussi le développement de la pédagogie des libertés en 1905 peut être compris comme la réalisation spontanée de ce programme, et comme le passage d'un premier type de vulgarisation du droit à un autre, dans un contexte politique favorable ${ }^{53}$.

Mais si l'on revient maintenant à la première question posée - qui faut-il éduquer ? - la réponse apportée par la pédagogie des libertés en 1905-1906 n'est pas aussi claire que le suggéraient les intentions affichées par auteurs et éditeurs.

51. E. Tarnovskij, Četyre svobody [Quatre libertés], SPb : Brokgauz-Efron, 1906 (Biblioteka samoobrazovanija), $77 \mathrm{p}$.

52. I.V. Gessen, « Juridičeskaja literatura dlja naroda (opyt kritičeskogo razbora) » [La littérature juridique pour le peuple (essai d'examen critique)], Pravo, no 47, 1901, col. 2035-2049 ; no 48, col. 2089-2101; n 49, col. 2164-2173.

53. Mišel’ Tis'e, « Kakoe juridičeskoe prosveščenie nužno v Rossii ? Perehod ot populjarizacii prava k populjarizacii graždanskih prav okolo 1905 goda » [Michel Tissier «Quelle éducation juridique pour les Russes? Le passage de la vulgarisation du droit à celle des droits civils autour de 1905 », Neprikosnovennyj zapas, n 44, 2005. 
Ceux-ci avançaient en effet des arguments très stéréotypés pour faire la promotion de leurs brochures : «tous publics », «à la portée de tous », «populaire ». Ces qualificatifs récurrents ne disent pas qui pouvait vraiment les lire. En majorité, elles n'étaient accessibles qu'à des lecteurs déjà passablement éduqués. Il ne suffisait pas d'être alphabétisé pour les lire ou pour se les faire lire et y comprendre quelque chose. Chez les auteurs, le souci d'adapter leur langage au lecteur populaire théoriquement visé était rare, ou l'adaptation maladroite. Dans certains cas, le lecteur populaire de ces brochures n'existait que dans l'imagination des auteurs ${ }^{54}$.

Aussi, en pratique, la pédagogie des libertés avait déjà tranché la question du lectorat en privilégiant non pas le peuple, mais un public qui aurait justement ressemblé à l'intelligentsia que Kistjakovskij voulait cibler. Cependant, cette catégorie reste trompeuse. Pour quelques brochures seulement, on peut se faire une idée assez précise du public potentiellement atteint, parce que les auteurs et leurs éditeurs exploitaient consciencieusement une certaine niche. C'est le cas des instituteurs que le pédagogue Dmitrij Ivanovič Tihomirov, avec sa revue Pedagogičeskij listok, connaissait bien dès avant 1905. Il publia à leur intention diverses brochures sur les libertés et les questions institutionnelles ${ }^{55}$. Encore faut-il observer que beaucoup d'instituteurs n'avaient même pas facilement accès aux moyens d'information et à la littérature spécialisée pour l'autoformation ${ }^{56}$.

De la confrontation entre les allégations de Kistjakovskij en 1909 et ce qu'on peut reconstituer de l'expérience des années 1905-1906 et de la période antérieure, ressortent donc les éléments suivants. D'abord, l'idée qu'il était nécessaire de développer une action éducative pour développer la conscience juridique des Russes était largement acceptée, de longue date. Ensuite, le moyen adopté pour y parvenir en 1905-1906, à savoir la pédagogie des libertés, avait contribué à relativiser le respect pour le droit positif impérial, car celui-ci n'était pas encore en état de garantir les libertés. Si Kistjakovskij relevait en 1909 le défaut de respect pour le droit en vigueur, il se refusait à nommer la tension irréductible au cœur de la culture juridique libérale qu'il défendait, manifestée par sa propre conception de la « conscience juridique ».

\section{La voie de la professionnalisation et la voie de la vulgarisation}

Leonard Schapiro, prenant la suite des auteurs de Vehi, considérait que la culture juridique libérale russe, pour être vraiment libérale, aurait dû prendre, après 1905 une seule direction. Les cadets, puisqu'il s'agit d'eux, auraient dû savoir reconnaître

54. S.A. An-skij, « Literatura intelligencii dlja naroda » [La littérature de l'intelligentsia pour le peuple], dans S.A. An-skij, Narod i kniga: opyt harakteristiki narodnogo čitatelja, M. : Universal'noe knigoizd-vo L.A. Stoljar, 1913, p. 34-38.

55. Sur les brochures de N.P. Družinin, voir supra.

56. Scott J. Seregny, « Professional Activism and Association among Russian Teachers, 18641905 », in Harvey D. Balzer, éd., Russia's Missing Middle Class : the Professions in Russian History, Armonk (NY) : M.E. Sharpe, 1996, p. 176. 
que c'était le moment de trancher dans le sens du respect de la légalité et du droit impérial, renouvelé par le manifeste du 17 octobre et par les lois fondamentales ${ }^{57}$. Telle était la position qui découlait du plaidoyer de Kistjakovskij pour le droit. Voilà pour l'orientation politique à prendre. Mais le problème de Kistjakovskij n'était pas seulement politique, même si les historiens, jusqu'à présent, se sont surtout intéressés à cet aspect ${ }^{58}$. Le problème était aussi d'ordre éducatif.

De ce point de vue, la proposition de Kistjakovskij était sans ambiguïté dans son article de 1909, même s'il la précisa par la suite ${ }^{59}$. Pour lui, le rôle d'éducateur devait revenir aux professionnels du droit, et en premier lieu à la corporation des avocats (prisjažnye poverennye) ${ }^{60}$. En 1909, sa vision des avocats comme profession était très négative. Il leur reprochait d'être à l'image de l'intelligentsia, uniquement préoccupée de politique, et non de défense du droit ${ }^{61}$. Aussi les éducateurs de la conscience juridique russe que devaient devenir les avocats avaient pour première tâche de s'éduquer eux-mêmes ${ }^{62}$. Plus généralement, les conditions de formation, de recrutement et de travail des avocats, mais aussi des autres professionnels du droit, devaient être soigneusement examinées et améliorées. L'éducation au droit était donc d'abord un objectif de perfectionnement à l'usage interne de ces professionnels. L'éducation au droit de l'ensemble de la population devait en découler naturellement. De même, l'espace dans lequel devait se déployer cette éducation était l'ensemble des lieux d'activité et de réflexion des professionnels : d'abord les tribunaux, mais aussi les sociétés juridiques ${ }^{63}$, les revues juridiques pratiques et savantes ${ }^{64}$, les universités et les établissements d'enseignement spécialisés. À cela

57. Schapiro, «The Vekhi Group...», p. 89-90 ; voir aussi Walicki, Legal Philosophies, p. 391-392.

58. Ce qui s'explique, si l'on resitue le travail des historiens sur le « libéralisme » russe dans le contexte des querelles sur les « responsabilités » des uns et des autres dans le désastre de la révolution d'Octobre 1917.

59. B. Kistjakovskij, « Naši zadači » [Nos tâches], Juridičeskij vestnik, 1, 1913, p. 3-17.

60. La bibliographie sur les avocats de l'Empire est d'autant plus importante que, déjà à l'époque, la corporation et ses membres les plus en vue se préoccupaient de faire connaître le plus possible leur histoire et leurs activités. Pour les travaux historiques postérieurs, voir Samuel Kucherov, Courts, Lawyers and Trials under the Last Three Tsars, NY : Frederick A. Praeger, 1953 ; Eugene Huskey, Russian Lawyers and the Soviet State : the Origins and Development of the Soviet Bar, 1917-1939, Princeton : Princeton University Press, 1986, p. 11-33 ; Jörg Baberowski, Autokratie und Justiz : zum Verhältnis von Rechtsstaatlichkeit und Rückständigkeit im ausgehenden Zarenreich 1864-1914, Frankfurt am Main : Klostermann, 1996, p. 481-614.

61. Kistjakovskij, «V zaščitu... »,p. 129.

62. Sur la question de la discipline parmi les avocats à Moscou, voir Jane Burbank, « Discipline and Punish in the Moscow Bar Association », Russian review, 54(1), 1995, p. 44-64. Kistjakovskij insistait sur la nécessité de discipliner la personne par le droit («V zaščitu... », p. 108), et l'exigence s'appliquait en premier lieu aux juristes.

63. Sur ces sociétés comme lieu de rassemblement des différents types de «professionnels du droit », voir Brian L. Levin-Stankevitch, « The Transfer of Legal Technology and Culture : Law Professionals in Tsarist Russia », in Balzer, éd., Russia’s Missing Middle Class, p. 241-242.

64. Heuman, Kistiakovsky, p. 32, sur l'implication personnelle de Kistjakovskij dans la renaissance de la société juridique de Moscou, et celle de sa revue, sous le nom Juridičeskij vestnik, en 1912-1913. 
s'ajoutaient les lieux où les juristes professionnels intervenaient au contact et au service de la population.

Insister sur cette voie de la professionnalisation n'était pas particulièrement original dans la période postérieure à 1905-1906. Ceux qui reprochaient à l'intelligentsia d'avoir tout subordonné à la politique, et qui considéraient que l'échec de la révolution signait la banqueroute de cette tendance, formaient alors une génération nouvelle ${ }^{65}$. Celle-ci substituait à l'engagement politique, jugé stérile, une action qu'elle voulait concrète, pratique et modernisatrice.

Les difficultés que rencontrait une telle démarche étaient cependant nombreuses. Il fallait compter avec la persistance d'incriminations pénales pour des faits considérés par les opposants au régime comme étant d'ordre politique, à quoi s'ajoutaient les mesures de répression administratives et militaires. Ces éléments relativisaient sérieusement les espoirs d'un Kistjakovskij, défenseur des libertés, d'assister à la dépolitisation du droit dans la société russe. Surtout, l'organisation même de la justice demeurait un obstacle au renforcement du rôle des professionnels du droit, et principalement des avocats, puisque la justice paysanne séparée se passait de leurs services. Les juristes libéraux avaient pour objectif d'uniformiser ce système dans la mesure où il leur paraissait perpétuer une inégalité des citoyens devant la loi. Ils ne considéraient pas le rapport des paysans à cette justice comme conforme à des principes juridiques dignes de ce nom ${ }^{66}$. Ces différents facteurs limitaient les ambitions des partisans de la voie de la professionnalisation dans le but de renforcer la culture juridique libérale. Ces derniers affichaient leur respect du droit positif, mais celui-ci, en l'état, ne facilitait pas leur emprise sur le fonctionnement de la justice. Leur projet n'avait de sens qu'à moyen ou long terme, et son apport à l'éducation juridique de la population paraissait incertain.

De plus, le développement remarquable de l'enseignement supérieur après 1905 fut beaucoup moins favorable au droit qu'aux autres grandes disciplines. Ce développement avait deux sources principales. D'une part, le gouvernement ouvrait de plus en plus de formations techniques, en partie pour répondre aux exigences croissantes de professionnalisation dans de nombreux secteurs. Des initiatives privées ou associatives, d'autre part, s'attachèrent à développer un enseignement supérieur ouvert à des publics dont l'accès aux universités impériales ${ }^{67}$ était impossible ou limité par des quotas, comme les femmes ou les personnes de confession non chrétienne, c'est-à-dire avant tout les juifs. Ces établissements indépendants restaient néanmoins sous la surveillance des autorités. Mais pour la plupart, comme l'université bien connue fondée par Šanjavskij à Moscou, ils n'étaient pas directement

65. I.V. Gerasimov, «Vse vlijanie "znajuščim ljudjam” : novaja generacija rossijskoj intelligencii kak modernizatory » [Toute l'influence aux «gens qui savent» : le rôle modernisateur de la nouvelle génération de l'intelligentsia russe], dans Vlast'i nauka, p. 282.

66. Frierson, « Rural Justice... »; pour une défense de cette justice, contre la vision des élites russes relayée par l'historiographie, voir Burbank, Russian Peasants..., p. 245-271.

67. De même que l'accès aux quelques établissements spécialisés, comme le lycée juridique Demidov à Jaroslavl', ou réservés à une élite, comme le lycée Alexandre ou l'École impériale de science juridique. 
concurrents des établissements impériaux ${ }^{68}$. Principale différence : leurs anciens étudiants ne pouvaient pas prétendre à un emploi dans l'administration. Dans le cas du droit, cette différence était rédhibitoire. Certes, des juristes de très grande qualité, et d'obédience libérale, trouvaient à enseigner dans ce genre d'établissements ${ }^{69}$ mais ceux qui entamaient des études supérieures dans une discipline comme le droit étaient d'abord motivés par les perspectives professionnelles. Et les principaux débouchés des études juridiques étaient offerts par le service civil, ou alors par le barreau. Or l'accès à ces carrières restait interdit ou restreint pour les femmes et les juifs. Dès lors la poursuite d'études de droit dans ce genre d'établissement ne pouvait qu'être un choix très marginal ${ }^{70}$. C'était en tout cas un choix déconnecté du modèle de la professionnalisation promu par les juristes libéraux eux-mêmes.

Parallèlement, qu'était-il advenu, après l'échec de la révolution de 1905, de l'autre voie éducative, celle de la vulgarisation, que Kistjakovskij semblait négliger en 1909 ? Il s'agit ici de mesurer les efforts éventuels, dans le pays, pour élargir l'éducation juridique au-delà des milieux professionnels ou, dans le cas des étudiants, orientés vers l'entrée en profession. Rien ne permet de supposer que la tendance à la professionnalisation était exclusive de nouveaux efforts pour vulgariser le droit. Au contraire, on pouvait penser que des possibilités existaient, à cause des réformes législatives des années 1905-1907 et des transformations de la culture juridique officielle à ce moment-là. D'une part, dans les établissements d'enseignement secondaire sous la tutelle du ministère de l'Instruction publique, des changements substantiels étaient intervenus depuis l'année scolaire 1905-1906, avec la réintroduction d'un enseignement de « science des lois » (zakonovedenie), d'abord dans les lycées classiques de garçons ${ }^{71}$. L'année suivante, la mesure fut étendue aux

68. A.A. Kizevetter, Na rubeže dvuh stoletij : vospominanija 1881-1914 [Aux confins de deux siècles : mémoires 1881-1914], M. : Iskusstvo, 1997 [1're éd. : 1929], p. 322-338.

69. Voir David Wartenweiler, Civil Society and Academic Debate in Russia, 1905-1914, Oxford : Clarendon Press, 1999, p. 189-215.

70. Voir le décalage dans les effectifs d'étudiants en droit entre les établissements impériaux et les établissements privés ou associatifs pour la période 1898-1916 (pour ces derniers, compte surtout l'après-1905), tel qu'il apparaît dans les tableaux statistiques établis par A.E. Ivanov, Vysšaja škola Rossii v konce XIX-načale XX veka [L'enseignement supérieur russe à la fin du XIX ${ }^{\mathrm{e}}$ siècle et au début du XXe], M. : Institut istorii SSSR AN SSSR, 1991, p. 318-320.

71. Un tel enseignement avait existé dans les établissements secondaires classiques entre 1849 et 1864 à titre obligatoire, puis à titre facultatif jusqu'en 1871, date de sa suppression. Cependant, au tournant du $\mathrm{XX}^{\mathrm{e}}$ siècle, la « science des lois » demeurait présente dans le cursus de deux types d'établissements secondaires, placés sous la tutelle d'autres ministères que celui de l'Instruction publique : certains établissements dépendant du ministère de la Guerre (notamment les classes supérieures des corps de cadets), et certains établissements d'enseignement commercial, réorganisés et mis sous la tutelle du ministère des Finances à partir de 1896. Voir V.E. Val'denberg, «O prepodovanii zakonovedenija v srednih učebnyh zavedenijah » [Sur l'enseignement de la science des lois dans les établissements d'enseignement secondaire], Žurnal ministerstva narodnogo prosveščenija [ŽMNP], no 11,1905 , otd. IV, p. 18-43; N. Čižov, « O prepodovanii zakonovedenija v srednih učebnyh zavedenijah ministerstva narodnogo prosveščenija » [Sur l'enseignement de la science des lois dans les établissements d'enseignement secondaire du ministère de l'instruction publique], ŽMNP, no 10, 1906, otd.IV, p. 59-75; E. Sinickij, « Prepodovanie zakonovedenija i razvitie pravosoznanija » [L'enseignement de la science des lois et le développement de la conscience du droit], Vestnik vospitanija, n 7, 1909, otd. I, p. 153-199. 
lycées d'enseignement «moderne » (real'nye učilišča). Il est vrai que les élèves concernés étaient appelés, dans une large mesure, à intégrer les universités impériales, et à devenir des professionnels, même dans d'autres domaines que le droit. Cette disposition pouvait donc, théoriquement, contribuer à renforcer la voie de la professionnalisation. Mais elle visait d'abord à diffuser la culture juridique officielle auprès d'un public plus vaste.

Les instructions officielles précisaient bien les limites de l'enseignement, qui devait apporter en priorité des connaissances sur la législation en vigueur dans l'Empire. Les questions d'histoire et de philosophie du droit, de même que la présentation des systèmes juridiques des autres pays d'Europe, n'étaient pas au programme. Il s'exerçait aussi une pression sur les manuels que les éditeurs indépendants publiaient comme supports de cours ${ }^{72}$. Des personnalités très conservatrices se plaignirent en 1908 auprès de l'administration sur le contenu de plusieurs manuels autorisés par le comité scientifique du ministère de l'Instruction publique ${ }^{73}$. Ces conditions contrevenaient à une exigence fondamentale de la voie de la professionnalisation que Kistjakovskij préconisait : celle de la liberté et de l'autonomie des professionnels du droit dans leurs débats internes, ce qui n'était pas contradictoire avec leur engagement à respecter la loi. De plus, les options «vulgarisatrices » de ces programmes ne servaient guère la culture juridique libérale ${ }^{74}$.

Hors de ce cadre, quelles étaient les possibilités d'une vulgarisation juridique systématique non officielle auprès de la population après 1905 ? Le secteur pouvait sembler porteur, car la vulgarisation scientifique et technique était en plein essor. Pourtant les questions juridiques étaient manifestement jugées trop sensibles pour faire l'objet d'une vulgarisation systématique. En effet, d'une part, le gouvernement s'efforçait d'effacer les traces de la pédagogie des libertés. Des auteurs ou des éditeurs de brochures sur les libertés, et sur d'autres questions institutionnelles, faisaient l'objet de poursuites des années après la publication des opuscules incriminés. Ce fut le cas pour une brochure publiée par la Commission sur la science des lois de la Section d'enseignement (Učebnyj otdel) de la Société pour la diffusion des connaissances techniques (Obščestvo rasprostranenija tehničeskih znanij, ORTZ), implantée à Moscou. Son auteur, P.I. Gal’berštad, était avocat. La brochure s'intitulait «L'inviolabilité de la personne et du domicile», elle s'appuyait sur des descriptions de la vie quotidienne des paysans et l'auteur avait

72. Parmi les premiers manuels publiés, voir V.A. Tomaševič, Učebnik zakonovedenija dlja gimnazij i real'nyh učilišč : kurs VII-go klassa gimnazij [Manuel de science des lois pour les gymnasia et les Realschule : cours de la classe de 7e], SPb, 1905.

73. RGIA (Rossijskij gosudarstvennyj istoričeskij arhiv - Archives historiques d'État de Russie), f. 776, Glavnoe upravlenie po delam pečati, op. 9, 1-e otdelenie, d. 1672, 1. 1, 3, 5-7, 12-14 : plusieurs manuels sont visés, dont un du même V.A. Tomaševič pour les élèves des établissements militaires, un autre destiné aux élèves des établissements secondaires classiques et modernes, et un dernier pour des écoles commerciales. Les auteurs durent apporter des modifications aux éditions suivantes de leurs manuels.

74. Pour en juger, il faut considérer non seulement le contenu des manuels, mais aussi le cadre institutionnel, matériel et humain dans lequel les cours de « science du droit » étaient dispensés dans les établissements scolaires. 
fait des efforts pour la rendre accessible à des lecteurs peu éduqués. Elle avait connu deux éditions, une en 1905, l'autre en $1906^{75}$. Les autorités de la censure à Moscou engagèrent des poursuites en 1910 contre l'éditeur et l'auteur. En 1912, la cour d'appel de Moscou ordonna finalement la destruction de tous les exemplaires saisis $^{76}$. La brochure ne relevait pas de la propagande politique partisane, mais son contenu ne pouvait pas plaire aux autorités. En 1905-1906, la Commission sur la science des lois de l'ORTZ projetait de publier une cinquantaine d'autres brochures sur des thèmes juridico-politiques, illustrant la culture juridique libérale. Seules deux brochures furent publiées au total.

D'autre part, le droit positif impérial était aussi relativement délaissé par les nombreuses initiatives de vulgarisation de l'époque. Au sein de l'ORTZ, la Section d'enseignement comptait dans ses rangs plusieurs juristes éminents ${ }^{77}$. Kistjakovskij y exerça des responsabilités entre 1907 et 1910, dans la Commission pour l'organisation de la lecture à domicile, la plus importante. Son but était précisément de favoriser la diffusion des publications scientifiques et techniques auprès de la population moscovite. L'activité de Kistjakovskij montre que, après 1905-1906, il n'avait pas perdu foi dans le travail pédagogique direct auprès de la population ${ }^{78}$. Mais l'absence d'allusion à ce type de travail dans son article de 1909, et l'insistance sur le rôle des juristes professionnels, pourraient bien être liées à un découragement ultérieur de Kistjakovskij devant la faiblesse des résultats obtenus. Dans la même région de Moscou, une association beaucoup plus petite, la Société pour la diffusion de l'instruction secondaire de la ville de Bogorodsk, organisait régulièrement des conférences, très générales, pour adultes. Entre 1909 et 1914, les juristes furent très peu nombreux sur l'ensemble des conférenciers invités. Les conférences, qui requéraient l'approbation des autorités locales, privilégiaient les sciences naturelles, la physique, et même l'histoire ${ }^{79}$.

En réalité, les seules possibilités véritables étaient celles d'une vulgarisation officielle ou semi-officielle du droit en vigueur. Des occasions existaient pour cela, à commencer par la mise en œuvre de la réforme agraire de Stolypin à partir de 1906. Le changement législatif concernait les paysans, il mettait en valeur l'initiative individuelle et proposait une vision de la liberté comme facteur de développement économique. La réussite de la réforme dépendait en grande partie de la capacité de l'administration à mobiliser toutes les ressources nécessaires pour faire

75. P.I. Gal'berštad, Neprikosnovennost' ličnosti i Žilišča [L'inviolabilité de la personne et du domicile], [2e éd.], [M.], [1906], 55 p.

76. RGIA, f. 776, op. 16, č. 2, 2-e otdelenie, d. 1273, 1. 1-6.

77. Voir la liste de ses membres au 1er janvier 1908 dans Otčet o dejatel'nosti Učebnogo otdela O. R. T. Z. za 1906 i 1907 gody [Compte rendu d'activité de la Section d'enseignement de la Société pour la diffusion des connaissances techniques], M. : I.D. Sytin, 1908, p. 106-112.

78. Heuman, Kistiakovsky..., p. 30-31, 163.

79. Central'nyj istoričeskij arhiv Moskvy [Archives historiques centrales de Moscou], f. 1589, Bogorodskoe obščestvo rasprostranenija srednego obrazovanija, op. 1, d.2, Protokoly zasedanij lekcionnoj komissii obščestva za 1909-1914 g., 1. 1-36 ob. 
connaître les nouvelles dispositions dans la population ${ }^{80}$. Une volonté de populariser les notions juridiques utiles pouvait s'appuyer, par ailleurs, sur l'essor des publications de vulgarisation en agronomie ou en économie rurale. Des publications périodiques à destination des paysans, officielles ou non ${ }^{81}$, contenaient des rubriques de conseils juridiques qui remportaient un succès certain.

Pourtant cela ne suffit pas à assurer à la vulgarisation du droit positif un véritable renouveau. Si cette littérature constituait avant 1905 un genre mineur, mais en développement, après 1907 elle survivait tout au mieux. Les informations juridiques présentées dans la presse périodique n'étaient pas négligeables ou méprisables, puisqu'au contraire elles répondaient aux demandes des lecteurs. Mais elles prenaient place dans le flot d'informations ou d'images sur le droit ou la justice qui caractérisait la presse périodique de l'époque, où dominaient les comptes rendus de procès criminels et les récits policiers ${ }^{82}$. Par contraste, les entreprises de vulgarisation du droit positif avant 1905 avaient souvent eu une perspective généralisatrice et systématique. La pédagogie des libertés en 1905-1906 eut le même genre d'ambition ${ }^{83}$. C'est seulement 1917 qui parut réhabiliter la voie de la vulgarisation chez les partisans de la culture juridique libérale, mais sans que la seconde expérience de pédagogie des libertés eut les moyens d'égaler celle de 1905.

80. Sur le difficile suivi local de la réforme, voir Judith Pallot, Land Reform in Russia, 19061917 : Peasant Responses to Stolypin's Project of Rural Transformation, Oxford : Clarendon Press, 1999, p. 126-155.

81. Sur le Sel'skij vestnik, qui publiait des rubriques de conseils juridiques bien avant 19051906, voir James H. Krukones, To the People : the Russian Government and the Newspaper Sel’skii vestnik («Village Herald»), 1881-1917, NY : Garland, 1987, p. 79-80, 258 ; Gaudin, «Tribunaux... », p. 115. Sur les périodiques apparus avec la réforme de 1906, comme Hutor ou Hutorjanin, voir Stephen P. Frank, «Confronting the Domestic Other: Rural Popular Culture and its Enemies in Fin-de-Siècle Russia », in Stephen P. Frank, Mark D.Steinberg, éd., Cultures in Flux : Lower-Class Values, Practices, and Resistance in Late Imperial Russia, Princeton : Princeton University Press, 1994, p. 104.

82. A.S. Izgoev, «Vospitanie demokratii » [L'éducation de la démocratie], Russkaja mysl’, no 7, 1909, otd. II, p. 202-208 ; Brooks, When Russia..., p. 207-213, 333 ; Joan Neuberger, Hooliganism : Crime, Culture, and Power in St. Petersburg, 1900-1914, Berkeley : University of California Press, 1993, p. 25-70.

83. Le bibliographe et vulgarisateur N. Rubakin, vétéran de la «pédagogie des libertés » de 1905-1906, écrivit en 1913 à la revue juridique Pravo, pour interpeller amicalement les juristes libéraux. Il les jugeait seuls à même de produire pour le marché russe le livre qui manquait : un «manuel pratique pour tous : utiliser et défendre ses droits civils et politiques ». Rubakin reconnaissait explicitement les progrès en matière de libertés depuis 1905. Mais il déplorait l'ignorance où la population était de ses droits, ce qui permettait aux autorités de les violer. Rubakin voulait y remédier par la publication d'un ouvrage systématique, à la fois encyclopédique et pratique, accessible au lecteur « du peuple » comme au lecteur éduqué non spécialiste. Cette initiative montrait une volonté remarquable de réinventer une vulgarisation du droit positif impérial réconciliée avec la pédagogie des libertés, s'appuyant sur l'un pour faire progresser les autres. Il n'y eut pas de suite connue à cette idée originale, restée isolée. Voir N. Rubakin, « Ob odnoj neobhodimoj knige (Otkrytoe pis'mo v redakciju žurnala "Pravo" » [Sur un livre nécessaire (Lettre ouverte à la rédaction de la revue Pravo)], Pravo, no 33, 1913, col. 1924-1926. 


\section{Conclusion}

Dans son tropisme éducatif, exacerbé en Russie, la culture juridique libérale englobait deux tendances qui insistaient chacune sur la priorité à accorder à un élément par rapport à l'autre : l'éducation aux libertés ou l'éducation au droit. Cette distinction n'autorise pas à exclure l'une ou l'autre tendance de la culture juridique libérale, laquelle n'est pas non plus la propriété des seuls libéraux dans le champ des luttes politiques - l'étiquette est d'ailleurs abondamment discutée, on le sait. La culture juridique libérale se caractérise précisément par la tension entre ces deux exigences. Cette tension en recouvre une autre, entre la politisation et la neutralisation de la culture juridique. Dans la culture juridique libérale, l'existence récurrente d'une tendance à la politisation ne suffit pas à disqualifier ceux qui en sont partisans au bénéfice de ceux qui la refusent : pour les mêmes, les positions peuvent changer dans le temps. Certes, apprécier l'opportunité de ces divergences sert de prétexte à certains historiens pour dire qui était libéral, et qui ne l'était pas. Mais cela ne prend guère en compte ce qui fait le cœur de la culture juridique libérale, en Russie ou ailleurs.

Le projet de dépolitiser la culture juridique après 1905-1906 a peut-être eu des résultats inattendus pour ceux qui en étaient partisans. L'insistance sur le rôle des professionnels du droit rencontrait un écho certain. Mais l'idée n'était pas de contribuer à relativiser la valeur universelle du droit, ni même celle des libertés. Or, une fois la voie de la vulgarisation laissée de côté, la voie de la professionnalisation contribuait à renforcer les frontières au sein de la population. Elle avait donc pour corollaire, bien involontaire, de promouvoir un particularisme, parmi d'autres. Cette voie apportait des renforts à la tendance qu'elle voulait combattre. Ce fut peut-être un handicap pour les partis politiques « libéraux » en 1917 - pas le seul, à coup sûr ! À supposer qu'elle eût pu avoir une quelconque efficacité, compte tenu de l'écart entre les intentions pédagogiques et les moyens utilisés, la pédagogie des libertés, quand elle resurgit en 1917, apparut dépassée, obsolète, par rapport à cet autre langage de la révolution, qui insistait sur les différences entre classes, entre «professions bourgeoises » comme les avocats et les professeurs, et le prolétariat. Le discours sur la valeur universelle du droit et sur la valeur universelle des libertés était encore moins audible en 1917 qu'il ne l'avait été en 1905. Mais le didactisme, lui, avait de beaux jours devant lui.

Université Paris I - Panthéon-Sorbonne

micheltissier@gmail.com 